International Journal of Management (IJM)

Volume 12, Issue 9, September 2021, pp. 19-31, Article ID: IJM_12_09_003

Available online at https://iaeme.com/Home/issue/IJM?Volume $=12 \&$ Issue $=9$

ISSN Print: 0976-6502 and ISSN Online: 0976-6510

DOI: https://doi.org/10.34218/IJM.12.9.2021.003

(C) IAEME Publication

Scopus Indexed

\title{
INFLUENCE OF MULTIDISCIPLINARY THINKING APPROACHES IN POVERTY ELIMINATION - CASE OF AFGHANISTAN
}

\author{
Mohamed Buheji \\ International Inspiration Economy Project- Bahrain
}

\begin{abstract}
Multidisciplinary thinking approaches, or holistic thinking, provides a unique opportunity to gain knowledge and solve chronic issues that come from a range of different subjects through the deeper understanding of patterns that are common between different complex issues. This type of thinking is important when dealing with complex problems like poverty elimination, or socioeconomic stability in a country that just came out of 40 years of war, like Afghanistan.

In this research, we investigate how multidisciplinary thinking approaches would address the new Afghanistan basic needs and enhance its capacity to address the needs of the poor and the vulnerable.
\end{abstract}

Key words: Afghanistan, Multidisciplinary Thinking, Post-War Afghanistan, Socioeconomic Issues, Poverty, Complex Issues

Cite this Article: Mohamed Buheji, Influence of Multidisciplinary Thinking Approaches in Poverty Elimination - Case of Afghanistan, International Journal of Management (IJM), 12(9), 2021, pp. 19-31.

https://iaeme.com/Home/issue/IJM?Volume=12\&Issue=9

\section{INTRODUCTION}

Multidiscipline holistic thinking solutions was always the major turning point for humanity, especially during unprecedented times. There are many solutions relevant to what we experience from 'quality of life' that is founded on the principle of multidisciplinary holistic thinking approaches, be it in education, health, social welfare, security, etc. However, humans over the last half-century have been too much busy with technology and science that are driven by sub-speciality. This type of extremely professional single-minded approach made humanity focus on what can make them more comfortable rather than what makes them bring a creative solution to many progressing socioeconomic problems. The significant focus on "comfort" rather than realized human development made a gap between the essence of life and solutions managed for everyday living. Buheji (2020a), OECD (2005).

In this paper we review the benefits of resilient multidisciplinary thinking in dealing with ill-structured complex chronic socioeconomic issues and how it made a differentiation. The uniqueness of the socioeconomic issues of Afghanistan are discussed in detail. Then demand 
for a holistic multidisciplinary thinking in reducing Afghanistan's poverty complexity is presented in the case study. Komlos and Benjamin (2019).

The case study shows the role of uncertainty in poverty elimination in Afghanistan's and the advantages of a multidisciplinary thinking in engaging the new generation in overcoming this challenge.

\section{LITERATURE REVIEW}

\subsection{Defining Multidisciplinary Thinking and related Approaches}

Realizing its importance to the educational outcome, UNESCO today encourages all the education channels to have effective approaches to curriculum integration. The UNESCO sees this could be done by one or more of the following approaches: multidisciplinary, interdisciplinary, and transdisciplinary. Buheji (2019a), Augsburg (2009).

The UNESCO (2020b) defines the multidisciplinary approach (which is the same as the cross-disciplinary approach), as studying one topic from the viewpoint of more than one discipline and solving a problem using a different disciplinary approach, Buheji (2020a). The socioeconomic example for this is the issue of poverty, which can be studied as a 'social equality issue', or it could be studied as an 'economic capability or competency' issue, Buheji (2019 a,b,c). The same would apply if we approach the pollution to the environment. The multidisciplinary approach for the elimination of emission pollution could be by two main routes. We can either improve the 'type of energy source used, which might be electrical, solar, petrochemical, etc., or by improving the 'engines designs', which leads to better performance which more of mechanical or electromechanical.

For the interdisciplinary approach, UNESCO (2020a) sees it as understanding theories that cut across disciplines and highlight the process and meaning rather than combining different discipline contents. For example, the design for the heart-lung machine required both mechanical engineering and medical knowledge to imitate the human organ's function.

In order to have an effective transdisciplinary approach, UNESCO (2020c) advises removing the boundaries between the core disciplines and integrate them to construct a new context of real-world themes. A good example of this is the inspiration economy (IE). The IE was developed as a transdisciplinary concept in 2015 by Dr Buheji, where economics has been integrated with positive psychology and behavioural sciences. Today, IE is spread to be an established interdisciplinary concept to solve real-life socioeconomic problems. Augsburg (2009)

The world is going towards more complexity as the sources of the problems are coming from a variety of reasons, especially those related to socioeconomic issues. The increase in the subspecialties and the emphasis of the capital economy-based solution drives towards a closed scarcity mindset. Therefore, the current and future world problems complexity requires both holistic multidisciplinary thinking and approaches. This would transform the way we deal with the complicated problems, i.e., the problems that need time \& financial resources but are not necessarily complicated in a complex world, as shown in Figure (1). Buheji (2020a) 


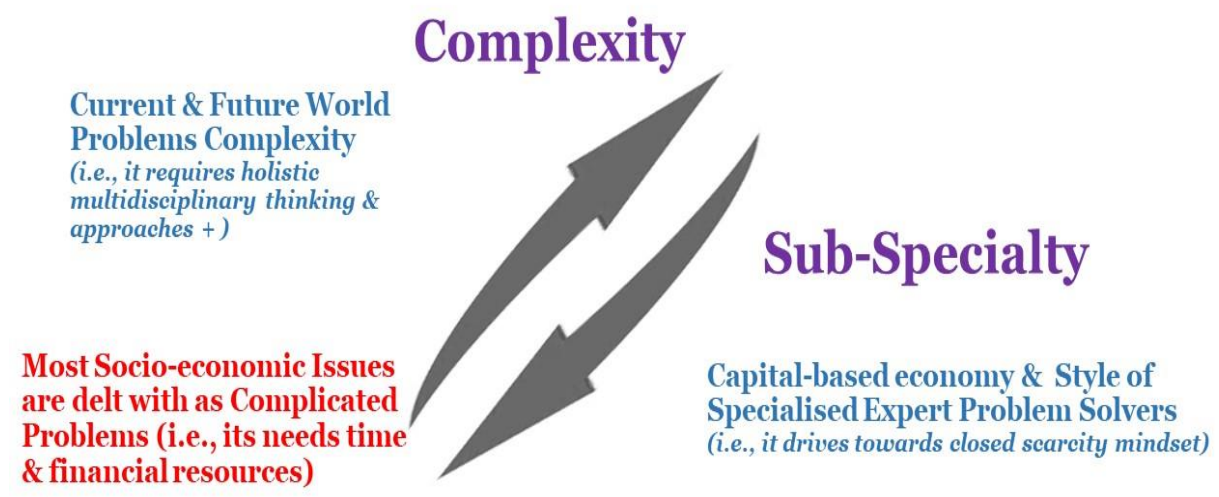

Figure 1 Shows the necessity of a multidisciplinary mindset for a rapidly increasing complex world.

\subsection{Benefits of Multidisciplinary Thinking in Dealing with Ill-Structured Complex Problems}

Multidisciplinary thinking nurtures the big thinkers and creative problem-solvers that society needs. The multidisciplinary thinkers focus on the elimination of errors, through critical thinking and productivity. The same is the interdisciplinary thinking which integrates science with professional skills through effective communication, and mentoring.

Multidisciplinary thinking raises the capacity to deal with complex adaptive systems. For example, in societies affected by a national emergency lockdown, multidisciplinary thinkers can create non-linear approaches to deal with unpredictable outcomes.

Multidisciplinary approaches build the capacity to overcome constrained problems with both convergent solutions and ill-structured problems. The mindset of a multidisciplinary professional can deal with the ambiguity and fuzziness while overcoming the noises and the environmental distractions. Through the holistic approaches, the multidisciplinary expert could see multiple solutions, or different paths towards a profound outcome. This type of mindset can bring common parameters and overcome the uncertainty necessary for effective solutions for wicked problems causing many socioeconomic instabilities and triggering conflicts. Buheji (2020a)

Complexity, a general term covering a wide range of complex, adaptive, emergent systems, and phenomena. Complexity recognizes the importance of orderly structures and institutions and the ability to make positivist claims about them. Complexity recognizes the uncertainty in all complex systems and their diversity. Sanderson (2000).

Multidisciplinary approaches help to match the intervention and system complexity in future studies, which leads to efficient problem-solving mechanisms. In a dynamic complex problem, multidisciplinary approaches could be a source of mental stimulation that helps in dealing with uncertainty and capturing opportunities, as per Figure (2). 


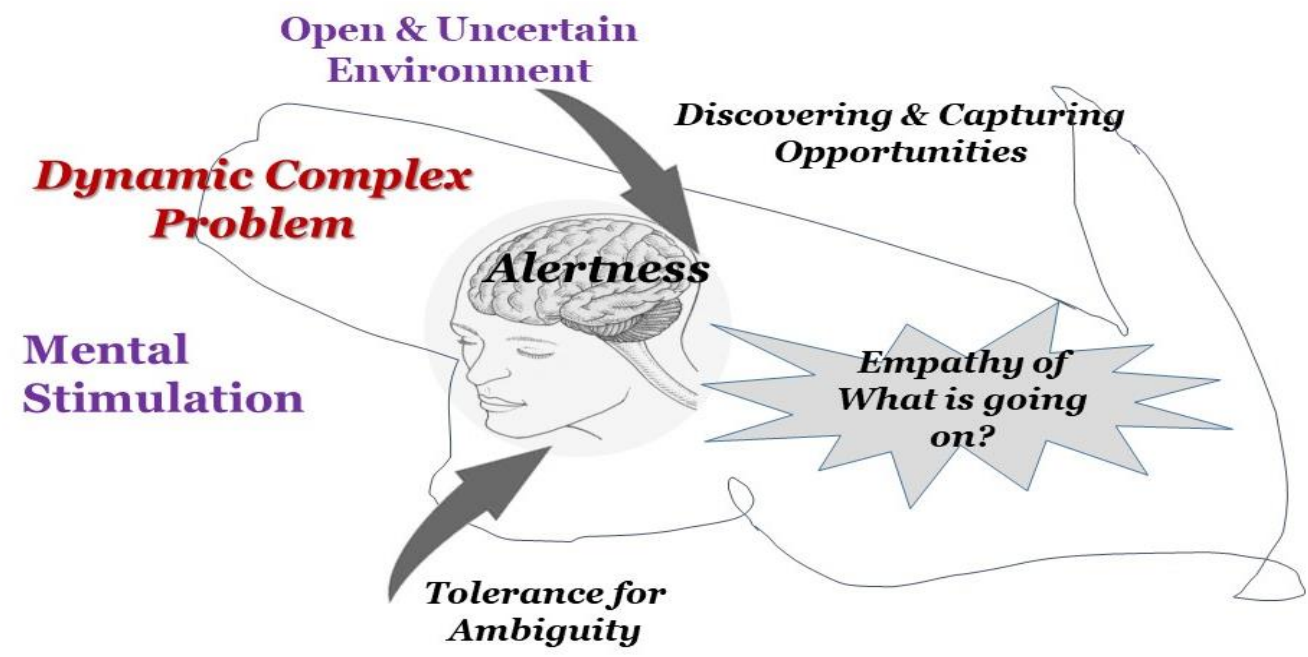

Figure 2 Illustrates how Multidisciplinary Thinking Works in Difficult times or when dealing with Complex Problems.

Complex systems are now interconnected and interdependent, which means that they are, by definition, more complex. Complex systems interact in unexpected ways. Sanderson (2000).

Multidisciplinary thinking brings teams that integrates information, data, techniques, tools, perspectives, concepts, and theories from more than two disciplines to solve problems whose solutions are beyond the scope of a single discipline or area of research practice. This type of thinking helps to focus on problems or questions that are too complex to be answered satisfactorily by any one discipline and from different perspectives. The best elements of disciplinary insights are integrated to generate a comprehensive appreciation of the issue at hand. This may come when we build new understanding and new meaning. Repko (2011)

\subsection{Role of Resilient Multidisciplinary Thinking in Solving Chronic Socioeconomic Issues}

Multidisciplined minds build a resilience capacity over time that help to build new layers in the communities they are serving in. Once tolerance becomes part of the practice, we, the multidisciplined professional, could universal contributions through having the capacity to visualize and deal with any complexity. Buheji (2018)

The effective multidisciplinary outcome requires resilient control of the field data during collection, and during interpretation. This resilience thinking help reduce the errors in observations and in the interpretations of the findings. In social science labs, such as the inspiration labs, how the data is collected in a specific environment setting is very important, since the data cannot be verified and calibrated as in physical science labs. Here, multidisciplinary thinking plays a great role.

Complicated socioeconomic issues are genuinely complex and have many moving parts, but they operate in patterned ways. With holistic perspectives, it is possible to make accurate predictions about how a complicated system will behave, Sanderson (2000). However, when the socioeconomic issue is not only complicated but clearly complex, by contrast, such poverty situation in Afghanistan compared to other places in the world. Buheji et al. (2020).

Resilient multidisciplinary thinking helps to avoid bias in observations collected for a major complex and complicated problem. This thinking brings in multi-different background observers to see the "hidden opportunities and what are the common dominators between them. Applying proper control to data collected with resilient thinking helps to refine the interpretation by rival causes, which give a chance to the multidisciplinary thinker to discover 
and/or exploit many overseen or hidden causes that lead to breakthroughs. The data management here has an important role in enhancing the creative outcome of any multidisciplinary process and minimize causes of intellectual humility, besides leads to further curios investigations. Buheji (2018)

\subsection{Problem-Solving Journey and Multidisciplinary Capacity}

The multidisciplinary perspectives enhance our holistic thinking and expand our capacity to see from different perspectives. The structure of the problem-solving labs followed by the inspiration economy help to spot potential developments and in tackling complex socioeconomic issues.

When a problem is redefined or reconsidered, we need to see the multiple meanings that would illustrate what type of investigation pathways or plans it offers. The quality of the reasoning of this problem is highly related to the level of ambiguity cleared. When multidisciplinary thinking is applied to the problem, the learning absorbed will not be dissipated or lost easily. The anxiety to dealing with complex problems also could be much less when the problem is quantified and estimated from a holistic setting.

Data needs to be collected in the abstract that it would lead to multiple interpretations. Having more than one meaning to specific analysis help to improve our understanding of what we observe or read, or hear. This multi- possible meaning enhances the ambiguity for what is observed in the beginning, but later open many possible connections, exploit, and associate many possibilities.

Having a collection of disciplines perspective in one's mind, or through the collection of peers, open multiple views that bring different perspectives with reasoning for chronic problems. The more choices or perspectives for a solution a problem have in the design solution, the more the type of decisions and actions could be taken.

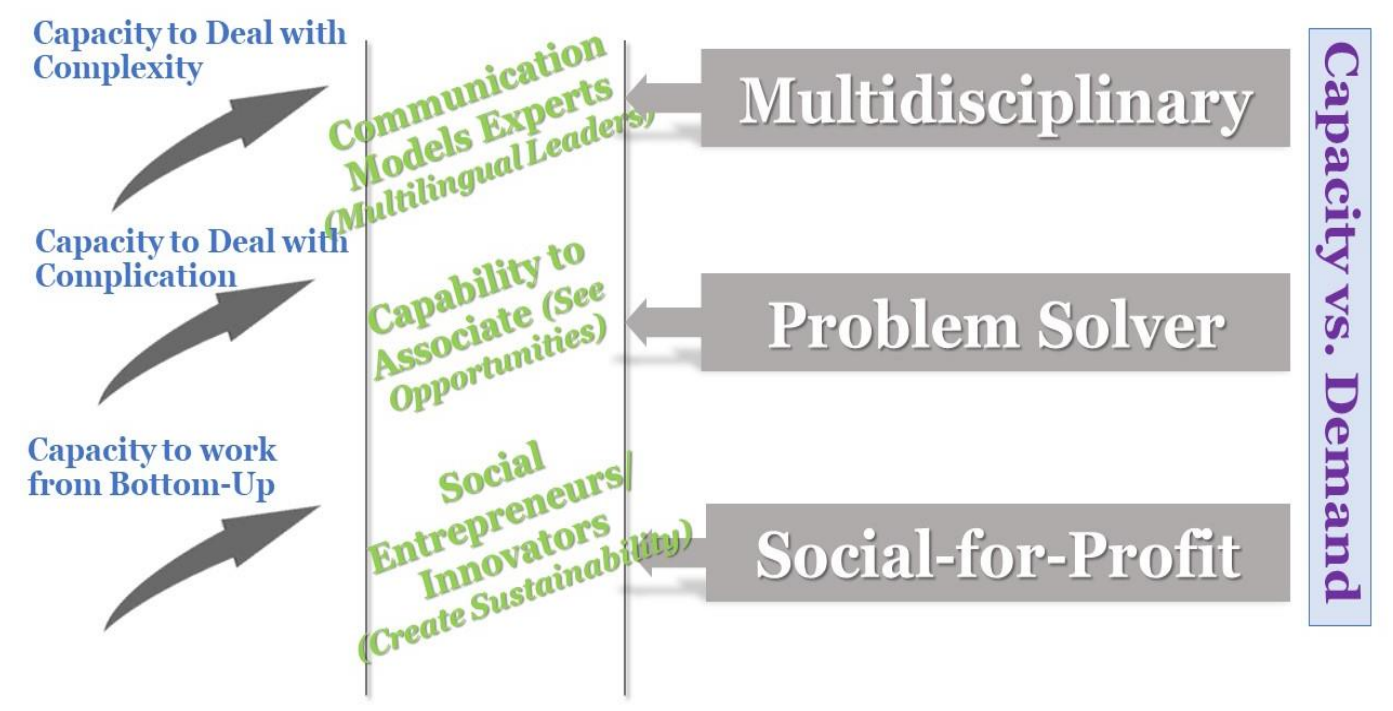

Figure 3 Role of Multidisciplinary Mindset in Creating better Capacity

\subsection{Profound Multidisciplinary Thinking Role in Change and Differentiation}

One of the main differentiation of a multidisciplinary mindset is its capacity to capture opportunities ahead of others. This capacity comes from being competent to observe and absorb specific reflections or reactions towards the specific issue, challenge, chances, opportunities, or problems. 
Studies show that profound multidisciplinary approaches help to create 'absorptive capacity' which comes because of challenges and the attempts for improvement with minimal resources. Multidisciplinary approaches bring in 'selective improvements' that leads to development, or selective investment that create an optimized outcome.

Multidisciplinary thinking differentiation comes in line with an accurate and precise collection of observations. These collected observations, once discussed from holistic perspectives, greater absorption and realization could be experienced, which leads to further development possibilities.

The interaction between the axis for 'nature of change' and 'sources of differentiation for multidisciplinary mindset' create proper suitable conditions of necessity, trigger change, bring in selective investment or development initiatives. Also, the integration between change and multidisciplinary mindset helps to develop opportunities, or associate the opportunities to bring in scientific appreciation, or create better capacity for making breakthroughs. This interaction is reflected in Figure (4).

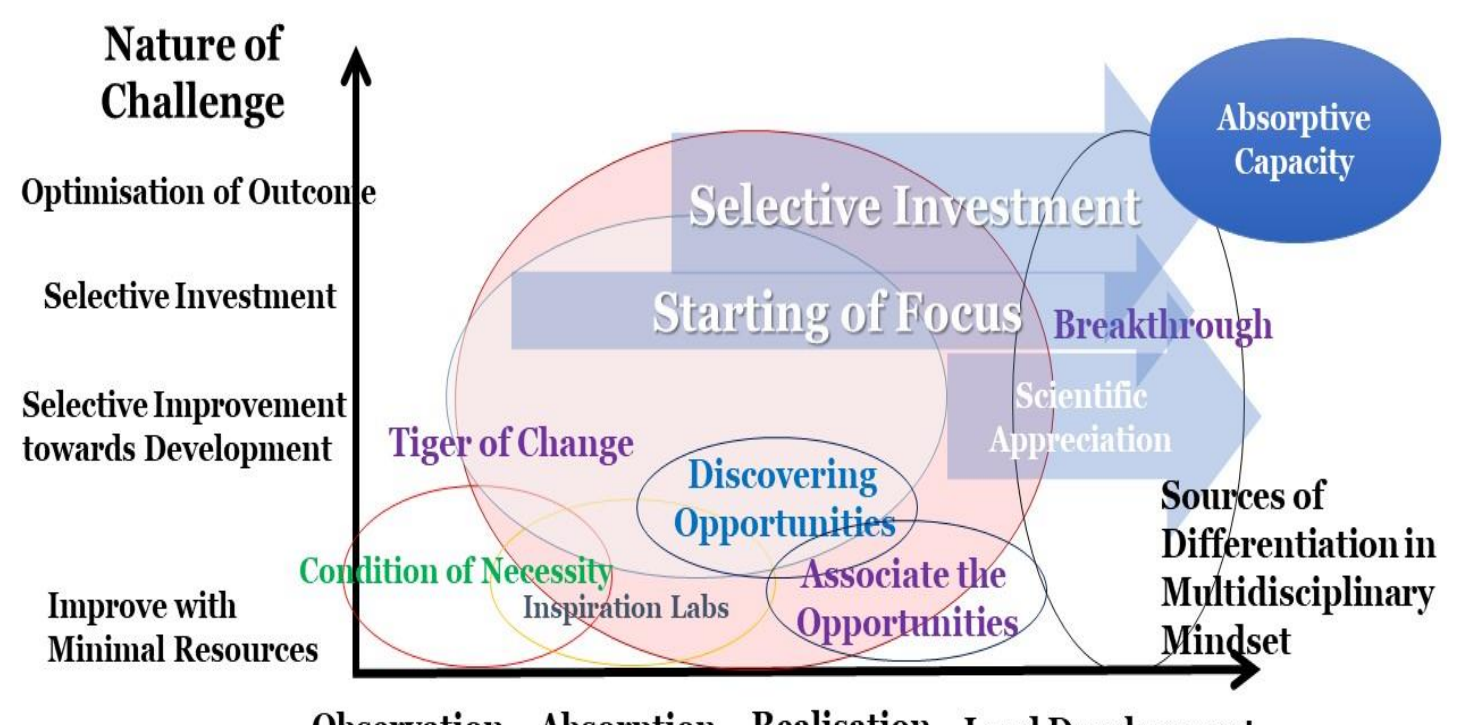

Observation Absorption Realisation Lead Development

Figure 4 Role of Profound Multidisciplinary Thinking in Creating Change and Differentiation Multidisciplinary Mindset

\subsection{Economy of Levels of Multidisciplinary Approaches}

Complexity reflects a specific status or an issue that is not being simple or being complicated or hard to understand. The analysis of complexity can be understood more by mathematical formulas that link between the requirements of life and the behaviours required for greater complexity. Complexity reflects the different components that are connected in the network which target to deliver specific functions or behaviours.

Complexity research and multidisciplinary thinking approaches could affect our contemporary and future life and livelihood, from many themes. Through realizing the complexities faced, we are tackling how to go about self-organizing that leads to the emergence of self-repair, and beyond. Repko (2011).

'Solution economy' is a term developed by Eggers and Macmillan (2013) to solve social problems from a multidisciplinary perspective which brings together different backgrounds as practitioners, academics, besides business, and government leaders to tackle a socioeconomic challenge or a problem holistically. 
All multidisciplinary approaches have their short- or long-term impact. While, a one disciplinary approach helps the researcher to realize in-depth the different concepts separately in each discipline, the 'multidisciplinary approach' helps researchers to realize the common theme of the different perspectives, besides the possible approaches in each discipline. Furthermore, an 'interdisciplinary approach' would help us to realize how one approach from the different concepts could be tightly linked. Buheji et al. (2021).

When multiple contributory causes become collective in impact, they are called complexity. Complexity as a phenomenon occurs in nature, or human, or humanity related systems or activities. The collection of these causes brings about complex events. Hence, for complex problems, if the problem could be dissected from a collective multidisciplinary approach, not knowing the causes is not an issue. Such an approach needs horizontal thinking that support dealing with complex issues.

Complexity emphasizes interactions through feedback loops; these feedback loops could be enlarged with multidisciplinary approaches and help to bring radical changes. Complexity characterizes the behaviour of a system and helps to create a model that interacts in multiple ways that enhance the possibility for different interactions that could bring solutions greater than the sum of its parts. Figure (5) shows the different approaches of multidisciplinary that fit the different complexity levels. The one discipline approach shows that having different concepts dealing with complex issues separately does not help to address the issue or deal with complexity, while having a multidisciplinary approach could bring more common themes of different perspectives of possible approaches in each discipline. Higher on the level of dealing with complex issues is the interdisciplinary approach, which helps to use one approach from concepts that are tightly linked. Then, finally, the transdisciplinary approach can help apply different concepts approaches to shape the final solution. Augsburg (2009)

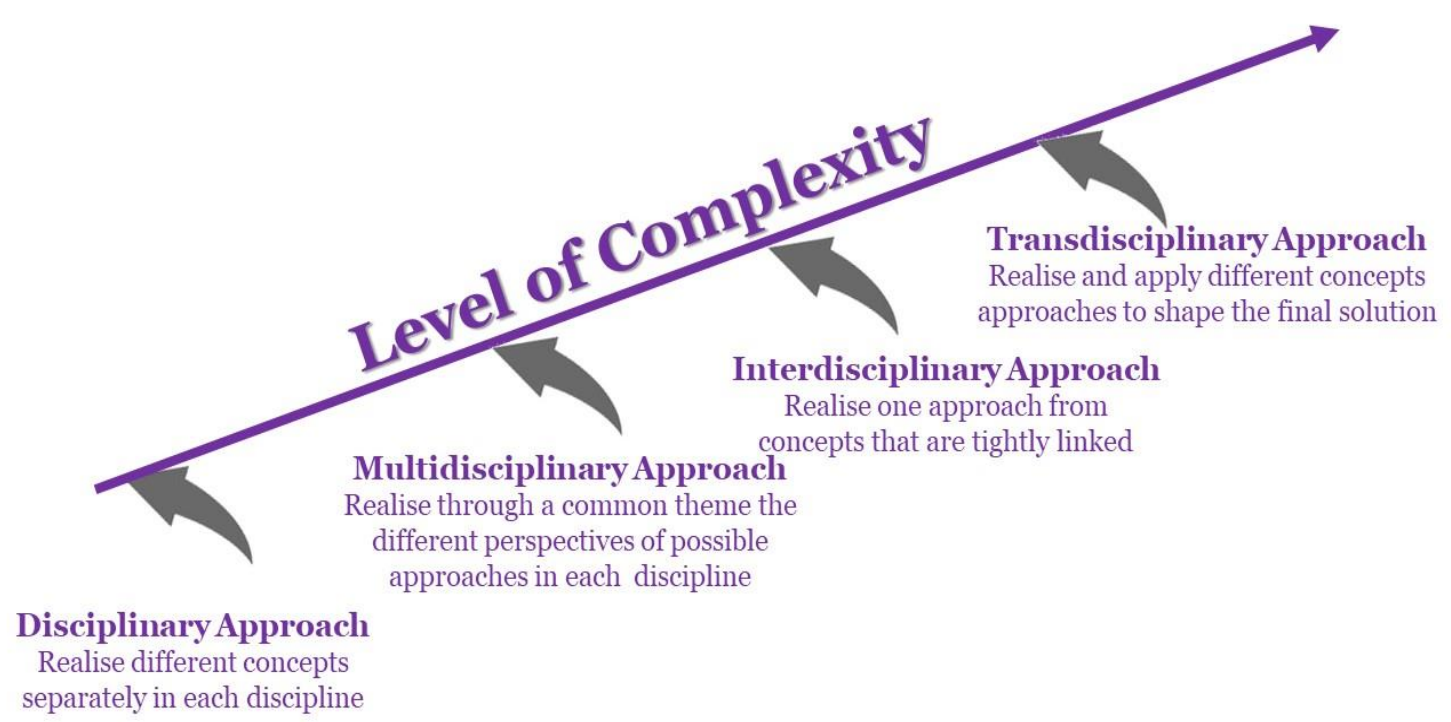

Figure 5 Levels of Complexity vs Multidisciplinary Approaches

Today behavioural scientists use complexity multidisciplinary research inputs by understanding how complexity works to solve unprecedented challenges. When there is a condition that requires multiple dimensions inputs, then demand diversity, intertwining and interdependence during the process of decision making is very high. The open, broad, and flexible capacity of thought brought by multidisciplinary thought enhance our comprehension 
of the world contemporary and future changes that mitigate the spillovers of any uncertainty. Repko (2011)

\section{CASE OF AFGHANISTAN}

\subsection{Uniqueness of Socioeconomic Issues of Afghanistan}

Afghanistan suffered a devastating socioeconomic instability after forty years of land occupation by the largest powers on earth, the Soviet Union and the united stated of America.

World Development Report (2000/2001) defines poverty as "unacceptable deprivation in wellbeing", where the absolute necessities for functioning are not available or rare. This definition also includes non-monetary poverty as fearing or living insecurity, experiencing poor health conditions, low education or illiteracy, lack of basic services, problems in social exclusion, lack of freedom, lack of empowerment and poor nutritional status. Besides, the definition of poverty includes the related monetary conditions as very low or no income, the capacity of purchase of consumption, capacity for household welfare. Buheji (2019a).

The World Bank (2021) reports Despite more than 6.9\% GDP growth in 2007-08 to 201112 , more than $36 \%$ of Afghans remained poor even in 2021. The lesson of more than 20 years of the American occupation of Afghanistan has not reduced poverty and where still more than one in three Afghans did not have the buying power to satisfy their basic food and non-food needs. Buheji and Korze (2020).

The studies show that poverty in Afghanistan strongly correlates to where people live, i.e., $80 \%$ of the poor live in rural and mountain areas. They have the lowest per capita consumption and highest likelihood of poverty. Asian Development Bank (2020)

\subsection{The Demand for Holistic Multidisciplinary Thinking in Reducing Poverty Complexity in Afghanistan}

There is a demand for a holistic approach at all levels of the Afghani society, to create a social, political, and economic environment that would allow people to reach their full physical, spiritual, mental, and emotional potential. Having or adopting policies that use a holistic approach to raise the capacity of every individual in Afghanistan to contribute to its development, regardless of race, sex, wealth or ability.

Three properties determine the complexity of any issue and where multidisciplinary approaches would be suitable. The first of these properties is multiplicity, which refers to the number of potentially interacting elements. The second of these properties is interdependence, which focuses on how connected those elements are. The third, diversity, has to do with the degree of their heterogeneity. The greater the multiplicity, interdependence, and diversity, the greater the complexity.

Poverty in Afghanistan has all these three complex properties as it contains a large number of interactive, interdependent, diverse elements. Through multidisciplinary approaches, we could identify and model the relationships between the parts; the relationships can be reduced to clear, predictable interactions simple and complicated systems.

When multidisciplinary thinking is embedded in the different analytic tools of the issue of poverty in a post-long-conflict country like Afghanistan, many highly interconnected parts of the issue would be taken into consideration, and we would ensure the diversity of thought. 


\subsection{Managing the Uncertainty of Poverty Elimination in Afghanistan through Multidisciplinary Thinking}

Afghanistan as a country suffers the worst duration in poverty. Poverty became more of chronic rather than transient. This increases the Afghanis vulnerability. Studies show that the patterns of growth contributed to widening the inequality. $20 \%$ of the poorest population saw a $2 \%$ decline in real per capita expenditure, while the richest $20 \%$ experienced a $9 \%$ increase. This is again why the vulnerability of the poor in Afghanistan is unique. To reduce poverty, Afghanistan must focus on strengthening human development and managing and mitigating risks that increase poor people's vulnerability.

Studies show that thinking patterns are highly correlated to the type and level of poverty, as these patterns can be both a cause and a consequence of poverty. Asian Development Bank (2020) reported that $47.3 \%$ of the population of Afghanistan lives below the national poverty line even in 2020.

In Afghanistan, poverty comes from the poor-quality jobs in the informal sector. The relatively low level of open unemployment is counterbalanced by the severity of underemployment. Therefore, the poor in Afghanistan are not only more likely to suffer from shocks, but also less equipped to deal with their consequences.

In order to raise our capacity to look beyond the complex challenges in current post-war Afghanistan, and establish trustworthiness, proactiveness culture towards the issue of poverty elimination, multidisciplinary holistic perspective thinking could be used. This type of selective development of Afghanistan socio-economy would help to mitigate many risks in the future and would eliminate any post-conflict spillovers known in certain situations. This uncertainty could be exploited more by both critical, curious thinking and clarity of purpose of what type of poverty need to be eliminated. Figure (6) shows how multidisciplinary thinking ease uncertainty in dealing with the issue of poverty elimination. Buheji (2020b), Buheji (2019).

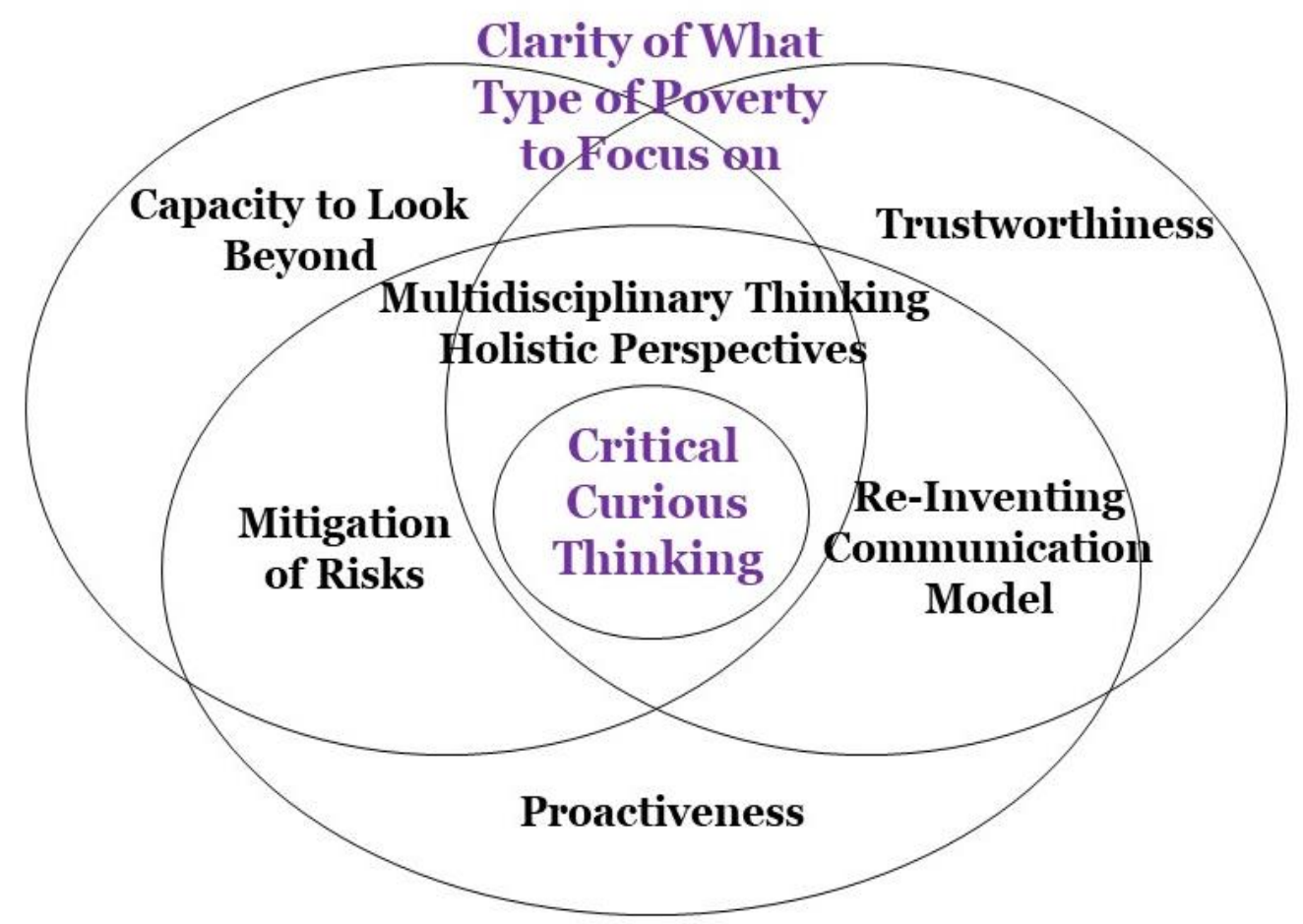

Figure 6 Management of Poverty Elimination Uncertainty in Afghanistan through Multidisciplinary Thinking 


\subsection{Advantages of a Multidisciplinary Approach in Future Development of Afghanistan Business}

Afghans are known to adapt to circumstances and conditions with common-sense approaches. If we manage to embed the multidisciplinary culture in the Afghanis youth where each individual has the well, the ambition and build the capacity to do not want to be just one thing, but is interested in becoming capable of being many things and whose interests move and shift in phases, we could overcome many obstacles that brought historical complexity and future complications.

Studies show that people whose expertise spans multiple disciplines can bring more depth and freshness into their varied fields. This means we would create a generation that is focused and committed to whatever field of business they may find themselves in.

\subsection{Importance of Multidisciplinary Approaches for Managing the New Generation of Afghanistan}

The situations and problems that come with many life and livelihood issues are multidisciplinary in nature, and thus require multidisciplinary behaviour and mindsets. The holistic approach about the intersections of complexity and complication, which Afghani multidisciplinary youth can bring, help to give a fresh new perspective to the traditional patterns.

Today's Afghanistan is not similar to Afghanistan, which was 20 years ago, at the time of the invasion of the US and NATO allies to the country when it comes to the type of youth and generation ambition. Many Afghanis are at the age of college students or considered to be Generation Z, who are characterized to be 'socially-conscious generation'. Afghanistan could benefit from the wealth of such generation and transform their youth economy currency towards commitment to social good, rather than dreaming only about migration. Dealing with such a generation with multidisciplinary approaches could influence Afghanistan socioeconomic development, as we could create a generation who believes in the future of the country, and it creates new purchasing power which would bring innovative career paths.

The commitment to establishing multidisciplinary programs in a post-war country like Afghanistan, which is still full of unexploited natural, physical, social and human capital resources, could help youth to aspire to create more social-for-profit companies that would be like a middle ground between a profit-driven company and a non-profit organization.

\section{DISCUSSION AND CONCLUSION}

The post-war knowledge could equip Afghanistan to go to a new level of speedy recovery and development if the thinking, the learning, the adapting, and the action are approached from a multidisciplinary perspective. All the non-capital assets, be it tacit- and explicit- need to be retrieved and transferred carefully through keeping them engaged in development or improvement projects within multidisciplinary teams, different communities or national or international wide.

Without extracting the accumulated physical, mental, spiritual knowledge within the different Afghani communities, it is difficult to see what lies beyond the uncertain of future and the spillovers of the new Taliban government. Developing a national multidisciplinary expertise hub is expected to play a potential role in the way the various aspects and challenges of new Afghanistan is defined. World Bank (2020)

One of the implications of this study is it encourages working with multidisciplinary teams in a collaborative manner to come with driven strategies and policies that are shared by Afghanistan stakeholders and the international community. The other practical implication of 
this paper is that it would give positive energy and inspiration among the Afghanis inside the country, or those who migrated, or thinking about migrating. This is specifically would be true if the accumulated knowledge and observations by the different multidisciplinary groups become appreciated and transformed to support the world understanding of the new Afghanistan and give it time and space for natural development.

Finally, this study shows that complex interventions in complicated social systems are highly dependent on their initial conditions. Therefore, the more we enhance the interaction between an expected mechanism within a specific context, i.e., in this case, the complexity of poverty in post-war Afghanistan, we can enhance the specific outcome needed.

In a nutshell, in order to build both complex and complicated adaptive systems during the unprecedented times similar to the 'Afghanistan case' we need to enhance the interaction, not reduce it, as shown in Figure (7). This need for complex adaptive systems during unprecedented times requires that the international community and the poverty elimination concerned stakeholders work on the following:

- Recognize the need for an updated framework that holistically addresses the complex socioeconomic issue of poverty in Afghanistan and mobilize community efforts.

- Use multidisciplinary thinking approaches to help in having an immediate selective response that raises Afghanistan capacity to deal with all the scenarios and overcome bottlenecks or barriers towards poverty elimination.

- Work on Afghani driven national capacity building programs that help to deal with nonlinear unpredictable occurrences of 'Sources of Poverty' in the different Communities.

\section{Recognise the need for an updated framework that address the complex socio- economic issue and mobilise community efforts.}

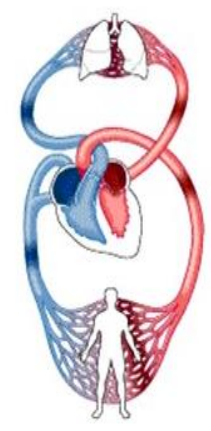

\author{
Immediate response \\ capacity that assess all the \\ scenarios and overcome \\ bottlenecks barriers.
}

\author{
Capacity to deal with non-linear \\ unpredictable occurrences that need \\ continuous assessment for the rapidly \\ changing situation.
}

Figure 7 Represent how to Build Socioeconomic Complex Adaptive System Similar to Poverty Elimination in Post-war Afghanistan

\section{REFERENCES}

[1] Augsburg, Tanya (2009) Becoming Interdisciplinary: An Introduction to Interdisciplinary Studies. Dubuque: Kendall-Hunt.

[2] Asian Development Bank (2020) Afghanistan: Fact Sheet https://www.adb.org/publications/afghanistan-fact-sheet 
[3] Buheji, M; Kuforiji, A; Fajana, S; Mavric, B and Beka, G (2021) Depth of Global Poverty and the Economy of Lockdown, International Journal of Management, 12(1), pp 460-474.

[4] Buheji, M (2020a) Easing Post-Pandemic Socio-economic 'Wicked Problems' through Exploratory Visits -Taking 'Generational Poverty' as an Example. International Journal of Management (IJM) Volume 11, Issue 12, December, pp.118-131

[5] Buheji, M (2020b) Review of Lessons Learned from the 'Asian Poverty Elimination Efforts' American Journal of Economics, 10(1): 5-10.

[6] Buheji, M; Korze, A (2020) Re-Emphasizing 'Geography Role' in Socioeconomic SolutionsA Pedagogical Approach Using Poverty Elimination as a Context. American Journal of Economics; 10(6): 459-465.

[7] Buheji, M; da Costa Cunha, K; Beka, G; Mavrić, B; Leandro do, Y; de Souza, C; Costa Silva, S; Hanafi, M; Chetia Yein, T (2020) The Extent of COVID-19 Pandemic Socio-Economic Impact on Global Poverty. A Global Integrative Multidisciplinary Review, American Journal of Economics, Vol. 10 No. 4, pp. 213-224.

[8] Buheji, M (2019a) Eliminating Poverty Through Educational Approaches-The Indian Experience, Review of European Studies; Vol. 11, No. 3; 32-44.

[9] Buheji, M (2019b) Re-defining Our Approaches to Extreme Poverty: An Attempt to Disrupting Contemporary Poverty Alleviation Approaches through Inspiration Economy Project- A Case Study, International Journal of Economics and Financial Issues, 9(4), 80-89.

[10] Buheji, M (2019c) Shaping Future Type of Poverty - The Foresight of Future Socio-economic Problems \& Solutions - Taking poverty as a Context- Beyond 2030, American Journal of Economics, 9(3): 106-117.

[11] Buheji, M (2019d) Poverty Labs- From 'Alleviation' to 'Elimination and then Prevention', Journal of Social Science Studies, 2019, 6(2): 108-122.

[12] Buheji, M (2019e) 'Re-designing the Economic Discovery of Wealth' a Framework for Dealing with the Issue of Poverty, International Journal of Economics, Commerce and Management United Kingdom 7(2): 387-398.

[13] Buheji, M and Ahmed, D (2019) The Intent - Shaping the future of Poverty Economy, Author House, UK. ISBN- 9781728392455

[14] Buheji, M (2018) Understanding the Power of Resilience Economy: An Inter-Disciplinary Perspective to Change the World Attitude to Socio-Economic Crisis, Author House, UK. ISBN978-1546286677

[15] Komlos, D and Benjamin, D (2019) Cracking Complexity: The Breakthrough Formula for Solving Just About Anything Fast. Nicholas Brealey Publication, USA.

[16] OECD (2005) Making Poverty Reduction Work, OECD'S Role in Development Partnership. https://www.oecd.org/development/34839878.pdf

[17] Repko, Allen (2011) Interdisciplinary Research: Process and Theory. 2nd. Ed. Thousand Oaks: Sage. Sanderson, I. (2000) Evaluation in complex policy systems. Evaluation, 6, p. 433-454.

[18] UNESCO (2020a) Interdisciplinary Approach, International Bureau of Education, http://www.ibe.unesco.org/en/glossary-curriculum-terminology/i/interdisciplinary-approach

[19] UNESCO (2020b) Multidisciplinary Approach, International Bureau of Education, http://www.ibe.unesco.org/en/glossary-curriculum-terminology/m/multidisciplinary-approach 
[20] UNESCO (2020c) Transdisciplinary Approach, International Bureau of Education, http://www.ibe.unesco.org/en/glossary-curriculum-terminology/t/transdisciplinary-approach

[21] World Bank (2021) Afghanistan Poverty Status Update

Overviewhttps://www.worldbank.org/en/country/afghanistan

[22] World Bank (2020a) Afghanistan Poverty Status Update

Overviewhttps://documents1.worldbank.org/curated/en/223041468189527489/pdf/100638-v1WP-P145128-PUBLIC-Box393238B-Nov-4-2015-WB-PovertyStatusOverview-v6.pdf

[23] World Bank (2020b) World Development Report 2000/2001: Attacking Povertyhttps://openknowledge.worldbank.org/handle/10986/11856

[24] World Bank (2013) Concept of deprivationhttps://www.worldbank.org/content/dam/Worldbank/Event/safetynets/5.\%20Yemt sov_Poverty\%20\%26\%20Vulnerability\%202013.pdf 